\title{
Pengaruh Variasi Diameter dan Jarak Nosel Terhadap Daya dan Efisiensi Turbin Pelton
}

\author{
Sarjono \\ Staf Pengajar (Jurusan Teknik Mesin, STTR Cepu) \\ E-mail: mbahjon1961@gmail.com
}

\begin{abstract}
The purpose of this study was to determine the effect of variations in diameter and number of nozzles on the power and efficiency of the Pelton turbine. The research method is experimentally using a miniature Pelton turbine installation with 3 nozzles. Variations in nozzle diameters of $4 \mathrm{~mm}$, $5 \mathrm{~mm}$, and $6 \mathrm{~mm}$ with a nozzle distance of $80 \mathrm{~mm}, 90 \mathrm{~mm}$, and $100 \mathrm{~mm}$ and variations in rotation from 300 to $700 \mathrm{rpm}$. The results showed that the nozzle diameter of $6 \mathrm{~mm}$ and the distance of the nozzle to the blade of $80 \mathrm{~mm}$ produced maximum turbine power and efficiency, namely 30.00 watts and $34.79 \%$, respectively.
\end{abstract}

Keywords: efficiency, nozzle diameter and spacing, pelton turbine, power.

\section{INTISARI}

Tujuan penelitian ini adalah untuk mengetahui pengaruh variasi diameter dan jumlah nosel terhadap daya dan efisiensi yang dihasilkan turbin pelton. Metoda penelitian secara eksperimen menggunakan instalasi miniatur turbin pelton dengan jumlah nosel 3 buah. Variasi diameter nosel $4 \mathrm{~mm}, 5 \mathrm{~mm}$ dan $6 \mathrm{~mm}$ dengan jarak nosel $80 \mathrm{~mm}, 90 \mathrm{~mm}$, dan $100 \mathrm{~mm}$ serta variasi putaran 300 sampai dengan $700 \mathrm{rpm}$. Hasil penelitian menunjukan bahwa pada diameter nosel $6 \mathrm{~mm}$ dan jarak nosel terhadap sudu $80 \mathrm{~mm}$ menghasilkan daya turbin dan efisensi yang maksimal yaitu sebesar 30,00 watt dan $34,79 \%$.

Kata Kunci: diameter dan jarak nosel, daya, efisiensi, turbin pelton.

\section{PENDAHULUAN}

Indonesia memiliki potensi yang sangat mendukung adanya sumber energi baru yang renewable sebagai sumber energi alternatif. Salah satu sumber energi alternatif yang dapat dikembangkan adalah pembangkit listrik tenaga air (PLTA). Penggunaan turbin air jenis mikro hydro merupakan salah satu pengembangan pemanfaatan energi terbarukan dengan kapasitas $\leq$ 100 KW (Dietzel, F., 1993).

Sistem mikrohidro telah dikembangkan di beberapa negara untuk memenuhi kebutuhan listrik di daerah pedalaman antara lain Peltric Set di Nepal, Columbian Alternator System di Kolombia, dan Pico Power Pack di Amerika. Ketiga sistem tersebut menggunakan turbin impuls sebagai penggerak (Maher and Smith, 2001).

Kinerja turbin pelton dipengaruhi oleh kualitas aliran jet. Kualitas aliran jet akan berpengaruh terhadap karakteristik aliran selama berinteraksi dengan permukaan sudu (bucket). Analisis aliran jet pada permukaan sudu turbin dilakukan secara numerik maupun eksperimen. Nosel yang dipakai dalam penelitian tersebut adalah tunggal dan berpenampang lingkaran. Hasil penelitian menunjukkan bahwa kualitas aliran jet berpengaruh pada distribusi tekanan dan medan kecepatan pada permukaan sudu sehingga terjadi peningkatan daya dan efisiensi turbin (Kvicinsky dkk, 2002).

Matthew Gass, (2002) telah melakukan penelitian dengan memodifikasi nosel. Sudut ujung nosel yang semula $60^{\circ}$ dan cincin dudukan (seat ring) $80^{\circ}$ diubah menjadi cincin dudukan $90^{\circ}$ dengan sudut nosel $50^{\circ}$. Hasil penelitian tersebut adalah adanya peningkatan efisiensi di atas $0.5 \%$ pada kondisi $60 \%$ beban penuh dan peningkatan sebesar $0.9 \%$ pada kondisi $100 \%$ pembukaan jarum.

Kemudian Purnomo (2011) dalam penelitiannya menyatakan bahwa nosel berpenampang segi empat dengan R:1,0 memberikan efek paling maksimal terhadap efisiensi turbin. Efisiensi turbin meningkat $18 \%$ jika dibanding dengan menggunakan nosel berpenampang lingkaran.

Jumlah nosel mempengaruhi kinerja turbin pelton mikro. Karakteristik jet aliran yang dihasilkan oleh nosel pada permukaan bucket yang optimal adalah pada jumlah nosel satu. Turbin pelton dengan jumlah nosel satu cocok diterapkan pada daerah potensi aliran air rendah, dan 
turbin pelton dengan jumlah nosel dua untuk potensi aliran air yang tinggi (Gatot Sumarno dkk, 2012).

Jarak nozzle berpengaruh terhadap daya listrik yang dihasilkan. Hasil maksimal terjadi pada kombinasi nozzle $3 \mathrm{~mm}$ dan $5 \mathrm{~mm}$ yaitu pada bukaan katup $85^{\circ}$ dengan hasil daya listrik sebesar 2,7 Watt (sri Purnomo, 2011).

Turbin Pelton adalah turbin impuls, yang prisip kerjanya mengubah energi potensial air menjadi energi kinetik dalam bentuk pancaran air. Pancaran air yang ke luar dari mulut nozzle diterima oleh sudu-sudu pada roda jalan sehingga roda jalan berputar.

Komponen utama turbin pelton adalah: Sudu turbin, Nosel, Rumah Turbin, dan Bracking Jet. Sudu turbin berfungsi untuk mengubah energi yang terkandung dalam air menjadi energi mekanik dalam poros turbin. Sudu turbin berbentuk mangkok, dipasang disekeliling roda jalan (runer blade). Nosel.berfungsi: (1) Mengarahkan pancaran air ke sudu turbin, (2) Mengubah tekanan menjadi energi kinetic, dan (3) Mengatur kapasitas air yang masuk ke turbin. Rumah Turbin berfungsi sebagai tempat dudukan roda jalan dan penahan air yang ke luar dari sudu-sudu turbin. Konstruksinya harus kuat untuk menahan teknan air dari runner blade.

Jika turbin akan dihentikan, nozzle harus ditutup rapat, tetapi karena adanya momen inersia dari runner blade dan peralatan lain yang terhubung padanya, biasanya runner blade tetap berputar untuk waktu tertentu. Untuk menghindarkan hal tersebut digunakan bracking jet yang menyemprot runner blde pada arah yang berlawanan.

\section{HASIL DAN PEMBAHASAN}

\section{Hasil Penelitian}

Hasil penelitian disajikan dalam tabel 1 sampai dengan 6 berikut ini.

Tabel 1. Hasil pengujian pada diameter nosel $4 \mathrm{~mm}$

\begin{tabular}{ccccc}
\hline Putaran $(\mathrm{rpm})$ & Kapasitas $\left(\mathrm{Q}: \mathrm{m}^{3} / \mathrm{s}\right)$ & Head $(\mathrm{H}: \mathrm{m})$ & Daya $(\mathrm{N}: \mathrm{W})$ & Efisiensi $(\mathrm{\eta}: \%)$ \\
\hline 300 & 0,000250 & 9,00 & 4,00 & 18,14 \\
400 & 0,000283 & 16,00 & 8,00 & 18,03 \\
500 & 0,000383 & 25,00 & 15,40 & 16,41 \\
600 & 0,000466 & 38,00 & 22,80 & 13,14 \\
700 & 0,000566 & 56,00 & 27,60 & 8,88 \\
\hline
\end{tabular}

Tabel 2. Hasil pengujian pada diameter nosel $5 \mathrm{~mm}$

\begin{tabular}{ccccc}
\hline Putaran $(\mathrm{rpm})$ & Kapasitas $\left(\mathrm{Q}: \mathrm{m}^{3} / \mathrm{s}\right)$ & Head $(\mathrm{H}: \mathrm{m})$ & Daya $(\mathrm{N}: \mathrm{W})$ & Efisiensi $(\mathrm{\eta}: \%)$ \\
\hline 300 & 0,000330 & 8,50 & 9,00 & 32,74 \\
400 & 0,000433 & 15,00 & 11,00 & 17,28 \\
500 & 0,000499 & 23,00 & 20.90 & 18,58 \\
600 & 0,000583 & 34,00 & 27.60 & 14,21 \\
700 & 0,000683 & 53,00 & 30,00 & 8,46 \\
\hline
\end{tabular}

Tabel 3. Hasil pengujian pada diameter nosel $6 \mathrm{~mm}$

\begin{tabular}{ccccc}
\hline Putaran $(\mathrm{rpm})$ & Kapasitas $\left(\mathrm{Q}: \mathrm{m}^{3} / \mathrm{s}\right)$ & Head $(\mathrm{H}: \mathrm{m})$ & Daya $(\mathrm{N}: \mathrm{W})$ & Efisiensi $(\mathrm{\eta}: \%)$ \\
\hline 300 & 0,000550 & 8,00 & 15,00 & 34,79 \\
400 & 0,000633 & 14,00 & 25,00 & 28,79 \\
500 & 0,000700 & 22,00 & 30,00 & 19,88 \\
600 & 0,000800 & 32,00 & 30,00 & 11,96 \\
700 & 0,000883 & 46,00 & 30,00 & 7,54 \\
\hline
\end{tabular}

Tabel 4. Hasil pengujian pada jarak nosel $80 \mathrm{~mm}$

\begin{tabular}{ccccc}
\hline Putaran (rpm) & Kapasitas $\left(\mathrm{Q}: \mathrm{m}^{3} / \mathrm{s}\right)$ & Head $(\mathrm{H}: \mathrm{m})$ & Daya $(\mathrm{N}: \mathrm{W})$ & Efisiensi $(\mathrm{\eta}: \%)$ \\
\hline 300 & 0,000220 & 6,80 & 3,50 & 24,96 \\
400 & 0,000250 & 8,60 & 5,00 & 26,62 \\
500 & 0,000305 & 12,10 & 9,10 & 29,15 \\
, 600 & 0,000360 & 15,60 & 13,20 & 30,24
\end{tabular}




\begin{tabular}{ccccc}
700 & 0,000410 & 18,80 & 18,60 & 30,12 \\
\hline \multicolumn{5}{c}{ Tabel 5. Hasil pengujian pada jarak nosel 90 mm } \\
\hline Putaran (rpm) & Kapasitas $\left(\mathrm{Q}: \mathrm{m}^{3} / \mathrm{s}\right)$ & Head $(\mathrm{H}: \mathrm{m})$ & Daya $(\mathrm{N}: \mathrm{W})$ & Efisiensi (n: \%) \\
\hline 300 & 0,000240 & 6,41 & 3,50 & 22,60 \\
400 & 0,000270 & 7,83 & 5,00 & 23,92 \\
500 & 0,000345 & 11,06 & 9,10 & 22,69 \\
600 & 0,000420 & 14,30 & 13,20 & 22,26 \\
700 & 0,000465 & 17,45 & 17,40 & 21,37 \\
\hline
\end{tabular}

Tabel 6. Hasil pengujian pada jarak nosel $100 \mathrm{~mm}$

\begin{tabular}{ccccc}
\hline Putaran (rpm) & Kapasitas $\left(\mathrm{Q}: \mathrm{m}^{3} / \mathrm{s}\right)$ & Head $(\mathrm{H}: \mathrm{m})$ & Daya $(\mathrm{N}: \mathrm{W})$ & Efisiensi $(\mathrm{\eta}: \%)$ \\
\hline 300 & 0,000250 & 6,30 & 3,40 & 19,55 \\
400 & 0,000290 & 7,60 & 5,00 & 20,57 \\
500 & 0,000375 & 9,95 & 9,10 & 19,13 \\
600 & 0,000460 & 12,30 & 13,20 & 18,64 \\
700 & 0,000510 & 19,95 & 16,20 & 17,00 \\
\hline
\end{tabular}

\section{Pembahasan}

Dari hasil pengujian, diperoleh grafik sebagi berikut. Gambar 1. adalah kapasitas turbin terhadap putaran pada variasi jarak nosel. Gambar 2 adalah head turbin terhadap putaran pada variasi jarak nosel

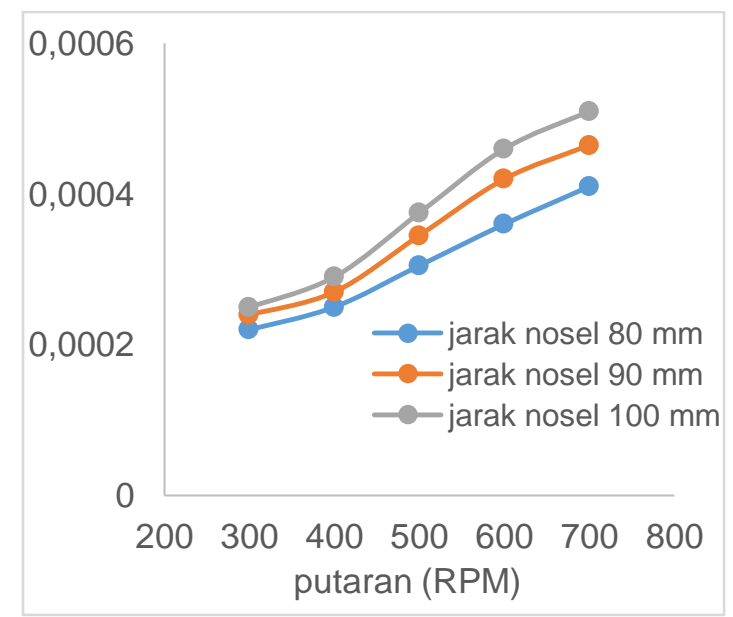

Gambar 1. Kapasitas turbin terhadap putaran pada variasi jarak nosel.

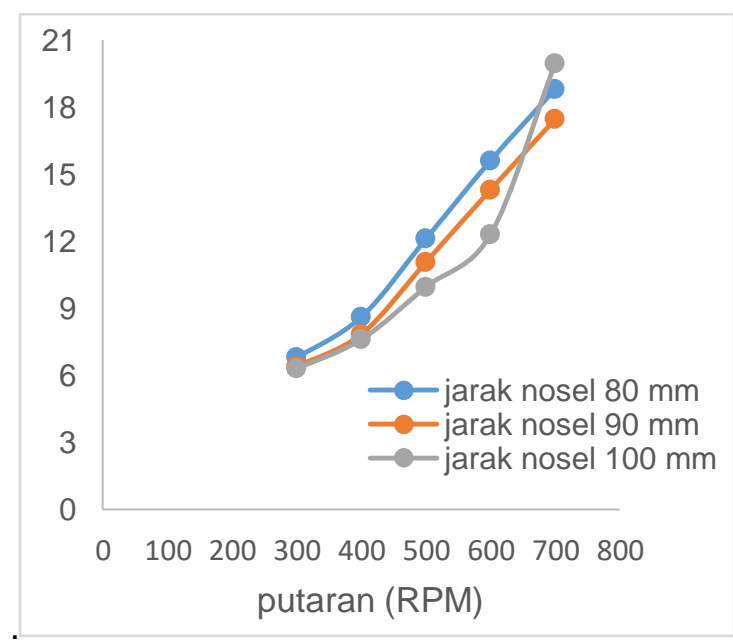

Gambar 2. Head turbin terhadap putaran pada variasi jarak nosel. 
Gambar 3. adalah grafik daya terhadap putaran turbin pada variasi diameter nosel $4 \mathrm{~mm}, 5$ $\mathrm{mm}$, dan $6 \mathrm{~mm}$.

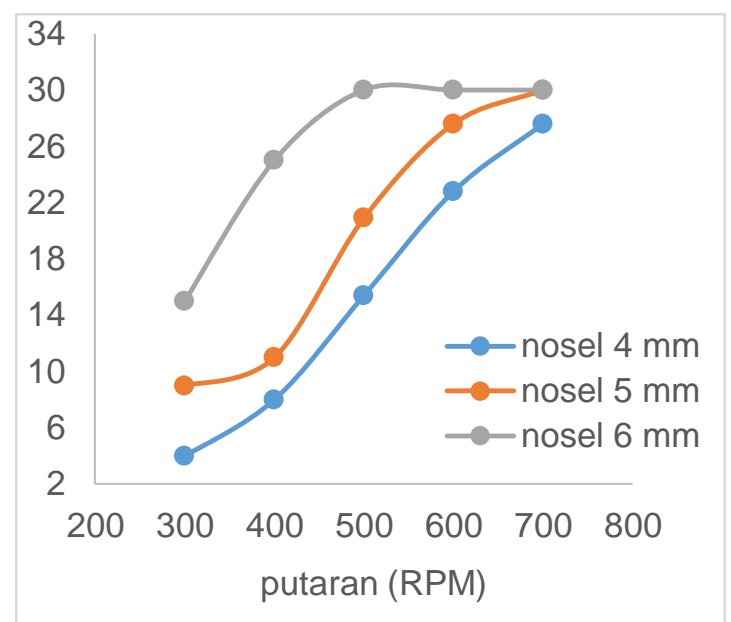

Gambar 3. Grafik daya tehadap putaran pada variasi diameter nosel

Gambar 3 menunjukkan bahwa daya maksimal yang dihasilkan oleh turbin adalah pada penggunaan diameter nosel $6 \mathrm{~mm}$, hal ini disebabkan oleh pembesaran diameter lubang nosel yang mengakibatkan peningkatan kapasitas air yang diterima oleh runner blade, sehingga akan menyebabkan terjadinya peningkatan daya yang dihasilkan oleh turbin. Pada gambar 4 menunjukkan daya yang dihasilkan turbin pada variasi jarak nosel $80 \mathrm{~mm}, 90 \mathrm{~mm}$, dan $100 \mathrm{~mm}$.

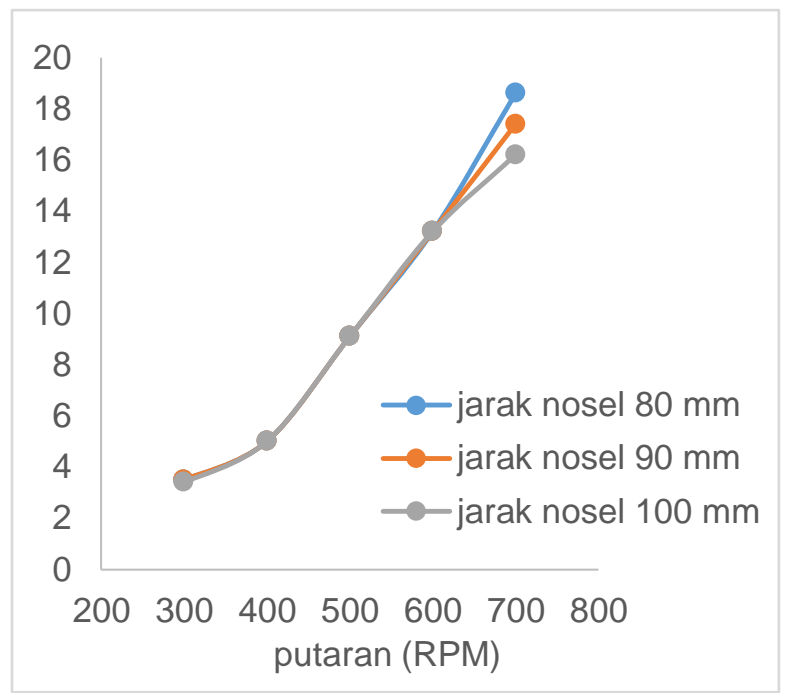

Gambar 4. Grafik daya terhadap putaran pada variasi jarak nosel

Pada jarak nosel $80 \mathrm{~mm}$ sebagaimana ditujukkan pada gambar 7 , daya yang dihasilkan oleh turbin adalah yang paling maksimal, hal ini disebabkan oleh tingginya kecepatan air yang memancar pada runner blade, sehingga putaran turbin akan semakin meningkat dan akan menghasilkan energi listrik yang maksimal. Pada jarak nosel yang semakin jauh dengan runner blade, kecepatan pancaran air semakin berkurang sehingga daya turbin yang dihasilkan semakin menurun.

Gambar 5 menunjukkan grafik efisiensi yang dihasilkan turbin pelton dengan variasi diameter nosel dan jarak antar nosel. 


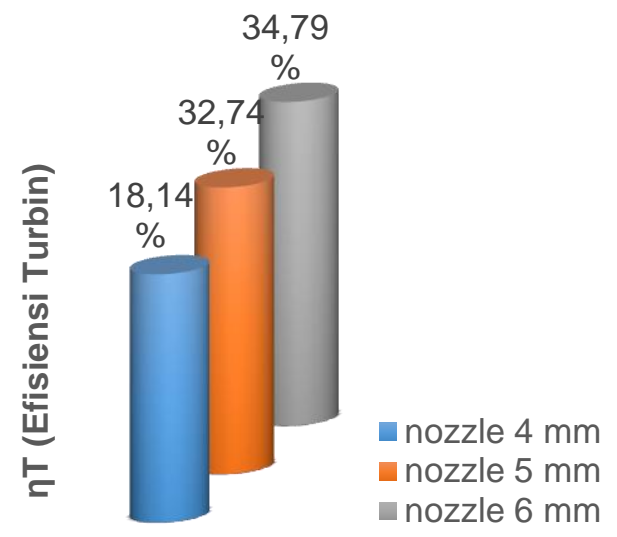

Gambar 5 Grafik perbandingan persentase efisiensi turbin pelton

Efisiensi maksimal sebesar 20,59\% dihasilkan oleh tuerbin dengan diameter nosel $6 \mathrm{~mm}$, hal ini disebabkan adanya peningkatan kapasitas air yang memutar runner blade sehingga akan menyebabkan daya yang dihasilkan meningkat.

\section{KESIMPULAN}

Hasil penelitian ini dapat disimpulkan daya turbin maksimal dihasilkan oleh penggunaan diameter nosel $6 \mathrm{~mm}$ dan jarak antar nosel $80 \mathrm{~mm}$, dengan ffisiensi turbin maksimal $34,79 \%$, terjadi pada penggunaan diameter nosel $6 \mathrm{~mm}$. Pada putaran 300 sampai dengan $700 \mathrm{rpm}$ variasi jarak nosel tidak tidak memberikan efek pada daya yang dihasilkan, tetapi setelah melewati putaran $700 \mathrm{rpm}$, dampak dari penggunaan jarak nosel $80 \mathrm{~mm}, 90 \mathrm{~mm}$, dan $100 \mathrm{~mm}$ mulai berbeda, karena kece;patan pancaran air yang tinggi akan menyebabkan putaran turbin semakin meningkat.

\section{DAFTAR PUSTAKA}

Dietzel, F., 1993. Turbin Pompa dan Kompresor, Erlangga, Jakarta.

Gatot Sumarno, Sahid, Sunarwo, 2012. Pengaruh Jumlah Nosel terhadap Unjuk Kerja Turbin Pelton Mikro Untuk Sistem Pembangkit Listrik Tenaga Mikro Hidro, Proseding Workshop dan Seminar Nasional Hasil-hasil Penelitian, Badan Penelitian dan Pengembangan Provinsi Jawa Tengah, Semarang.

Kvicinsky.S, JL Kueny, F Avellan, E Parkinson. 2002. Experimental and Numerical Analysis of Free surface flows in A Rotating Bucket. Proceedings of the xxist IAHR Symposium on Hydraulic Machinery and Systems. Lausann.

Maher, P, Smith, N., 2001, Pico Hydro for Village Power, Practical Manual for Schemes Up to $5 \mathrm{~kW}$ in Hilly Areas.

Matthew Gass, 2002, Modification of Nozzles For The Improvement of Efficiency of Pelton Type Turbines, Hetch Hetchy Water and Power, Moccasin Ca USA.

Muhammad Irsyad, 2010, Kinerja Turbin Air Darrieus Dengan Sudu Hydrofoil Standar Naca 6512, Jurnal Ilmiah Teknik Mesin, volume 1 Nomor 2, Universitas Lampung.

Sri Purnomo, 2011 Pengaruh Jarak dan Ukuran Nosel Pada Putaran Sudu Terhadap Daya Listrik Turbin Pelton, Teknik Mesin, Universitas Gunadarma. 